\title{
GAS RADÓN Y SALUD LABORAL EN CANARIAS
}

Luis Enrique Hernández Gutiérrez Juan Carlos Santamarta Cerezal José Luis Gutiérrez Villanueva 


\section{Gas radón y salud laboral en Canarias}




\section{Gas radón y salud laboral en Canarias}

Luis Enrique Hernández Gutiérrez Juan Carlos Santamarta Cerezal José Luis Gutiérrez Villanueva

San Cristóbal de La Laguna, enero de 2019

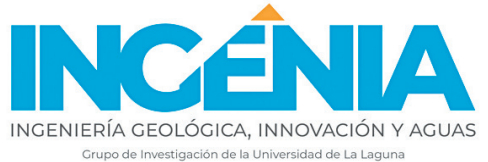




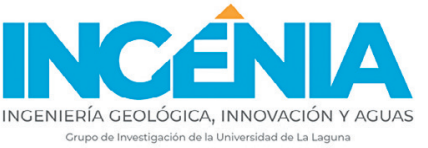

INGENIA (Ingeniería Geológica, Innovación y Aguas)

Grupo de investigación de la Universidad de La Laguna

https://ingeagua.webs.ull.es/index.html

e-mail: jcsanta@ull.es

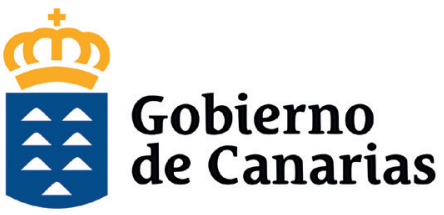

Proyecto financiado por la Consejería de Empleo, Políticas Sociales y Vivienda del Gobierno de Canarias (c) Los autores

Universidad de La Laguna

ISBN:978-84-09-08401-2

Depósito legal: TF 46-2019

DOI: 10.25145/b.Gasradon.2020 
La presente publicación tiene carácter divulgativo y pretende hacer llegar a los trabajadores de la Comunidad Autónoma de Canarias la información básica sobre un problema de salud laboral hasta ahora poco conocido en esta región, los efectos del gas radón.

La publicación se contempla en las actividades del proyecto de investigación financiado por la Consejería de Empleo, Políticas Sociales y Vivienda del Gobierno de Canarias, que lleva por título: «Desarrollo de procedimientos de protección de la salud de los trabajadores contra los riesgos derivados de la exposición al gas radón en lugares de trabajo de la Isla de El Hierro: Una experiencia piloto para Canarias». El proyecto fue realizado por la Fundación Canaria General de la Universidad de La Laguna (FGULL).

El proyecto se enmarca en el Plan de Actuación del Instituto Canario de Seguridad Laboral 2017-2018, que tiene como objetivos generales, la mejora continua de las condiciones de seguridad y salud en el trabajo, la reducción continuada de los accidentes de trabajo y enfermedades profesionales, y el avance en la implantación de una cultura preventiva.

La redacción de esta publicación ha correspondido a los siguientes miembros del equipo de investigación del proyecto:

Luis Enrique Hernández Gutiérrez

Dr. en Ciencias Geológicas

Juan Carlos Santamarta Cerezal

Dr. Ingeniero de Montes

José Luis Gutiérrez Villanueva

Dr. en Ciencias Físicas 


\section{Índice}

1. Introducción .......................................................................... 11

2. Radiactividad y radiaciones ionizantes ........................... 12

3. ¿Qué es el radón? ................................................................... 16

4. Efectos sobre la salud del gas radón ............................ 20

5. Normativa de aplicación en materia de seguridad

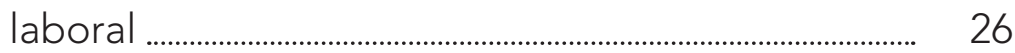

6. El radón en lugares de trabajo de Canarias ............... 30

7. Sistemas de medida de concentración de radón .. 35

8. Procedimiento de evaluación de la exposición al radón en lugares de trabajo .......................................... 38

9. Recomendaciones de prevención y mitigación ....... 50

10. Bibliografía de consulta ........................................................ 54 


\section{Introducción}

En esta publicación encontrará información sobre el radón, un gas radiactivo natural que puede suponer un importante problema de salud laboral en los territorios volcánicos, como es el caso de las Islas Canarias.

La normativa española en el ámbito de la seguridad laboral, establece la obligatoriedad de los titulares de determinados lugares de trabajo de declarar la situación en que estos se encuentran en cuanto a las radiaciones ionizantes que pueden afectar a sus trabajadores. Los territorios volcánicos son considerados por el Consejo de Seguridad Nuclear (CSN) como "áreas identificadas», ya que requieren de especial atención pues pueden generar y favorecer la emisión de radiación ionizante producida por el radón.

En los últimos apartados se proponen recomendaciones para la evaluación de los lugares de trabajo de la Comunidad Autónoma de Canarias frente a las radiaciones ionizantes por radón, en cumplimiento de la normativa obligatoria vigente en España, y para la prevención de la salud de los trabajadores. 


\section{Radiactividad y radiaciones ionizantes}

El descubrimiento de los rayos $X$ realizado por Wilhelm Conrad Roentgen en 1895 (premio Nobel en física en 1901) suscitó el interés de otros investigadores que pretendían determinar el origen de los mismos. Así, la radioactividad fue descubierta en París accidentalmente por Henri Becquerel en 1896, cuando experimentaba, con sales de uranio y con unas placas fotográficas, la producción de rayos $X$ por acción de los rayos del sol. El cielo se nubló unos días y guardó en un cajón de su laboratorio las sales junto con las placas; su sorpresa fue que las placas quedaron intensamente impresionadas, deduciendo que la radiación provenía del uranio contenido en las sales. Años más tardes, trabajando en la misma línea, Marie Sklodowska Curie (Madam Curie) y su marido Pierre Curie descubrieron el elemento químico Polonio (1898), bautizado con ese nombre en honor a la patria de Marie (Polonia).

El matrimonio Curie fue galardonado con el premio Nobel en Física, en 1903, el mismo año en que lo recibió también Becquerel, en reconocimiento a su investigación del fenómeno de la radiación. Marie Curie volvió a recibir en 1911 el premio Nobel en solitario, en esta ocasión en Química, por el descubrimiento de los elementos Radio y Polonio. Ahí no quedarían los logros científicos en el campo de la radiación de la familia Curie, ya que su hija Irene Joliot-Curie recibiría el premio Nobel en química en 1935 por sus síntesis de elementos radiactivos. 


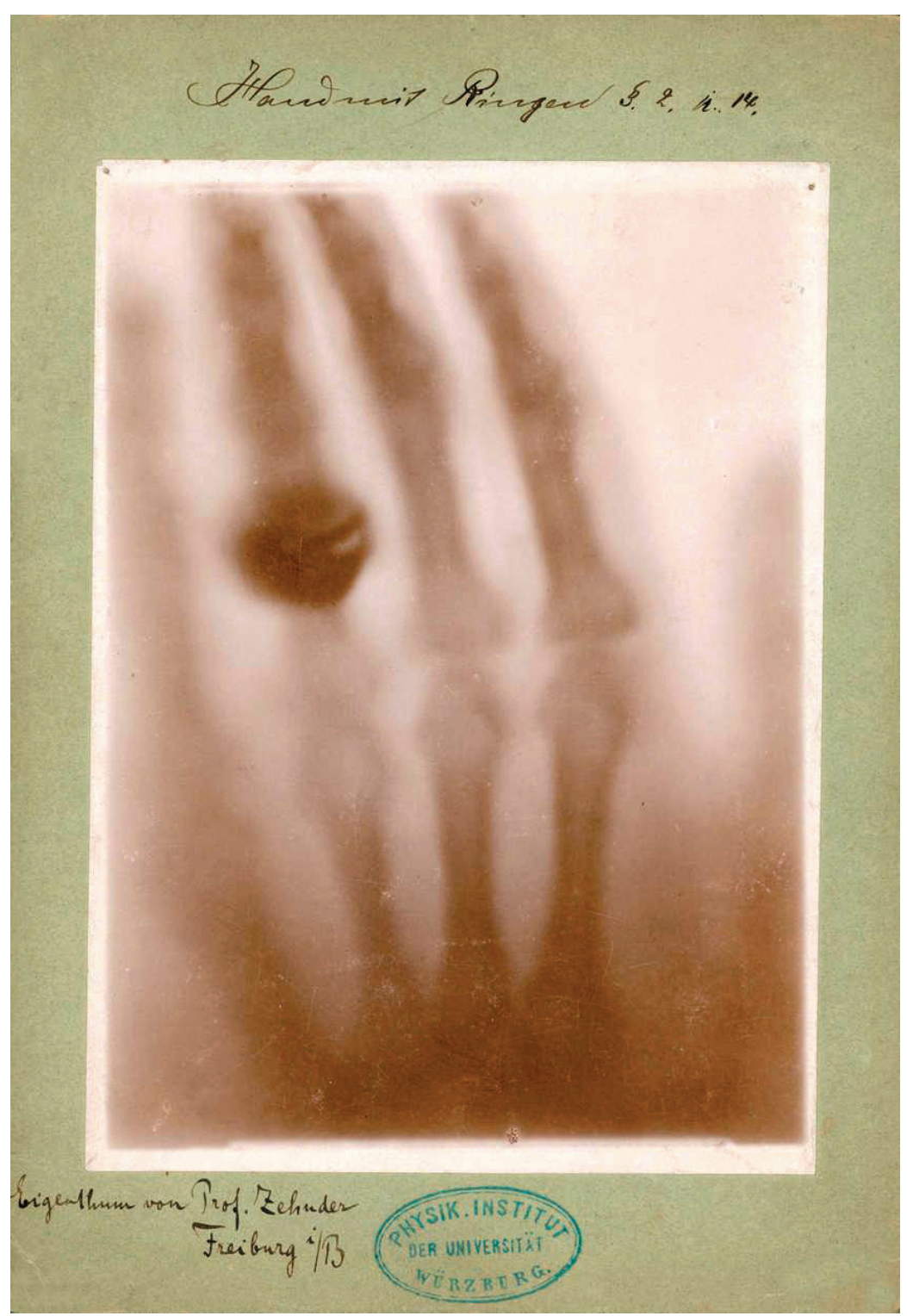

Radiografía de la mano de la esposa de Wilhelm Conrad Roentgen, descubridor de los Rayos-X y premio Nobel en física en 1901. 


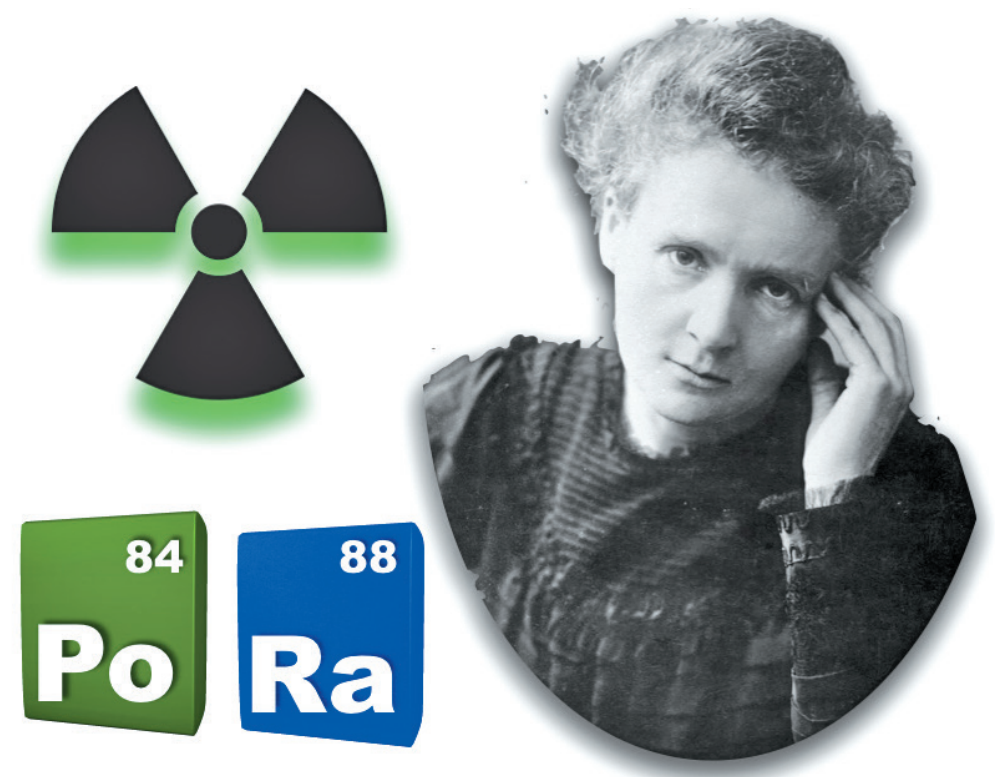

Marie Curie, premio Nobel en Física (1903) y en Química (1911) por sus estudios sobre la radiactividad y por el descubrimiento de los elementos Radio y Polonio.

La emisión de radiación por parte de los elementos atómicos está asociada a los denominados isótopos radiactivos. La estructura de los átomos se puede simplificar en un núcleo formado por protones y neutrones, con una nube de electrones que lo rodea. Un elemento atómico tiene un número fijo de protones en el núcleo, pero el número de neutrones puede variar, dando lugar a distintos isótopos de ese elemento. Los isótopos pueden tener núcleos estables o inestables. Los primeros mantienen el mismo número de protones y de neutrones de forma permanente, pero los segundos pueden perder neutrones con el paso del tiempo y dar lugar a nuevos isótopos; a estos se les conoce como isótopos radiactivos o radionucleidos. 
Así pues, la radiactividad es una propiedad por la que los isótopos radiactivos se desintegran dando lugar a nuevos isótopos y emitiendo a la vez radiaciones en forma de partículas (alfa, beta, neutrones, protones) o radiación gamma. Al conjunto de estas radiaciones se las conoce como radiación ionizante, porque al interaccionar con la materia que la rodea puede disociarla formando iones.

Es indudable que el descubrimiento de la radiactividad ha traído grandes avances en muchos campos para la humanidad (sanidad, energía, industria, etc.). Especialmente, es destacable lo importante que ha sido el radiodiagnóstico en el ámbito sanitario. Pero también es cierto que el exceso de radiación es perjudicial para la salud de las personas, de ahí la importancia de controlar y conocer no sólo la cantidad de radiación que recibimos sino también las fuentes de las que proviene.

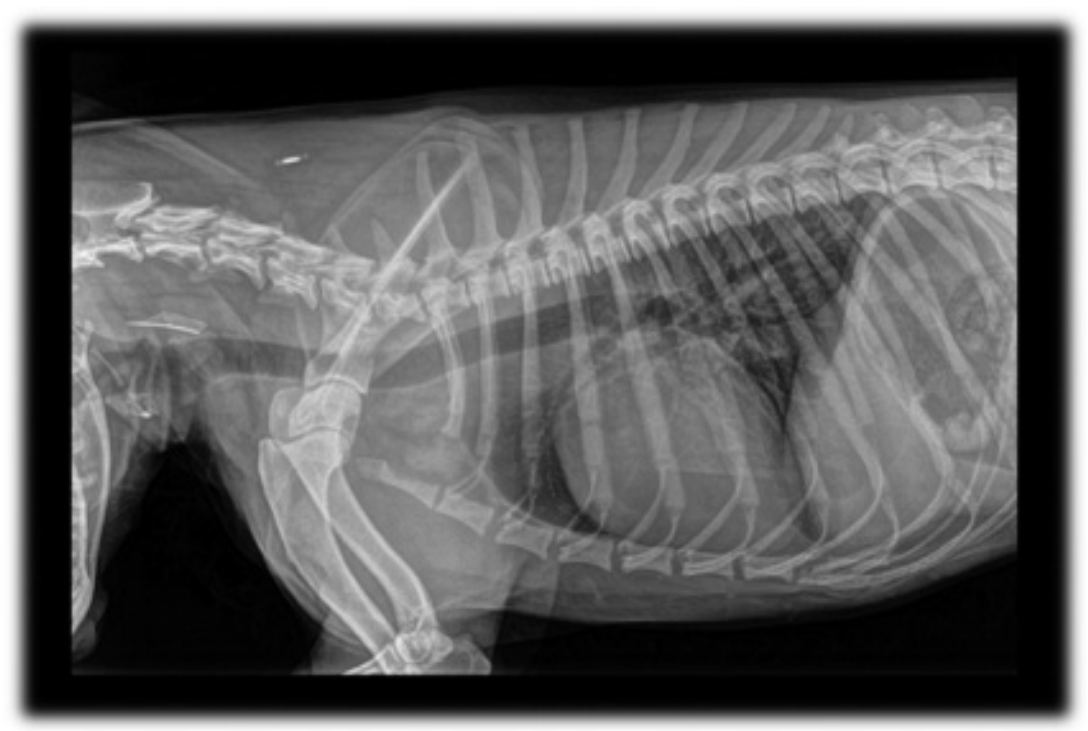

\section{Radiografía del costado de un perro.}




\section{3. ¿Qué es el radón?}

El radón es un elemento químico que se encuentra en la tabla periódica formando parte del grupo de los gases nobles. Como es conocido, los elementos de este grupo se caracterizan por ser gases sin color, sin olor y por su baja reactividad química, es decir, que prácticamente no se combinan con otros elementos para formar otros compuestos químicos.

Atendiendo al significado del adjetivo «noble» como «carente de maldad o doble intención», debemos decir que el radón no es un gas tan «noble» como el resto de gases de la tabla periódica, como veremos.

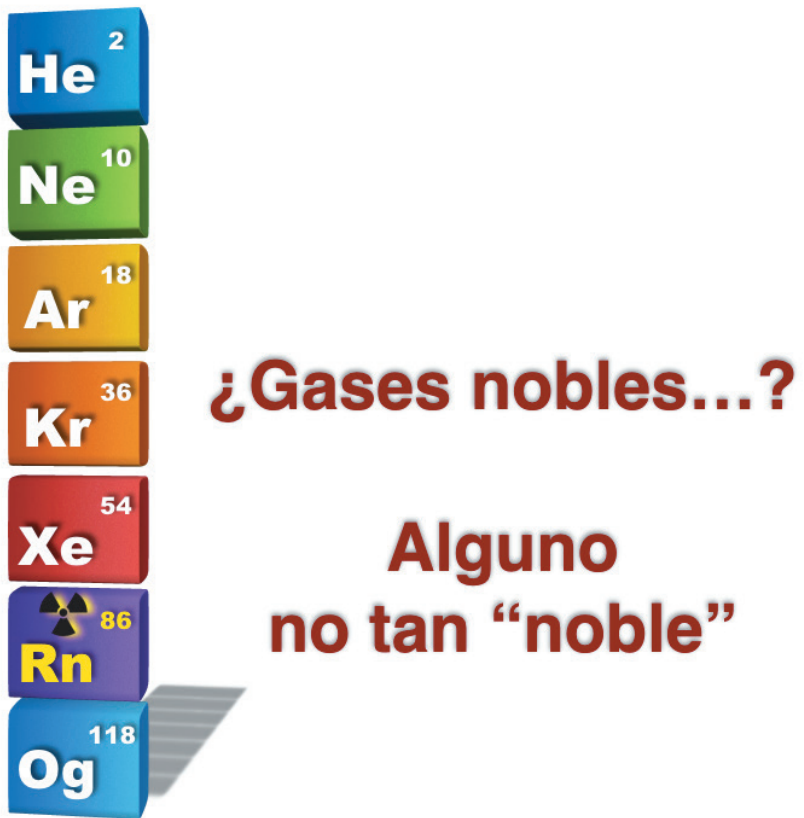

Gases nobles de la tabla periódica de los elementos. 
El radón es un elemento radiactivo que tiene distintas formas de presentarse en la naturaleza (isótopos radiactivos) y una de ellas, la más estable y abundante, es el Rn-222, en adelante simplemente radón. Este isótopo del radón es el que aquí nos ocupa. Otros isótopos del elemento químico radón son el torón (Rn-220) y el actinon (Rn-219). Pero debido a sus vidas medias extremadamente cortas generalmente el isótopo interesante desde un punto de vista de protección radiológica es el radón o Rn-222.

La cadena de desintegración de los elementos atómicos que participan en la generación del radón (Rn-222), se inicia con el uranio (U-238), pasando por el torio, radio y finalmente radón. Todos los elementos mencionados anteriormente aparecen en la naturaleza en estado sólido, pero el radón lo hace como gas.

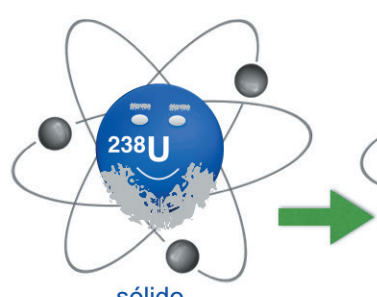

sólido

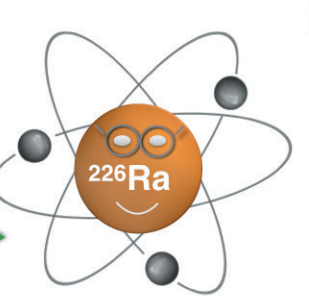

sólido

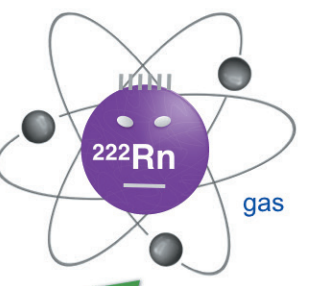

El Radón 222 es un isótopo radiactivo gaseoso que proviene de la desintegración del Radio 226 (sólido), que a su vez proviene de la cadena de desintegración del Uranio 238 (sólido). 
El Rn-222 aparece por la desintegración de otro isótopo radiactivo, el Ra-226 (Radio 226). La vida media del Rn-222 es de 3 a 4 días (3,8 días), en ese momento se transforma en Po-218 (polonio 218), emitiendo partículas alfa; a su vez, este último continúa la cadena de desintegración dando lugar a distintos isótopos radiactivos hasta que finalmente se forma el Pb-206 (plomo 206) que es estable.

Debido a que el radón es un gas de origen natural, se encuentra presente en la corteza terrestre a través de la exhalación del radio. De esta forma puede encontrarse tanto en el terreno, el agua, los materiales de construcción y particularmente en el interior de los edificios. Su presencia en el agua es posible gracias a su excelente solubilidad en este medio y de esta manera puede viajar grandes distancias desde su fuente de origen. Es por ello que las fuentes de entrada de gas radón en un edificio son fundamentalmente tres en orden decreciente de importancia: el terreno sobre el que está el edificio construido, los materiales de construcción y el agua. De esta forma nos encontramos con un elemento muy común que constituye la principal fuente de exposición a la radiación natural a la que se encuentra sometida el público en general. Aproximadamente el $50 \%$ de la dosis radiactiva natural recibida por la población a lo largo de un año se debe a la exposición al gas radón; el resto se debe a los rayos cósmicos del sol y otras estrellas, a la radiación gamma natural de la corteza terrestre y a los radionucleidos que ingerimos en alimentos y agua. 


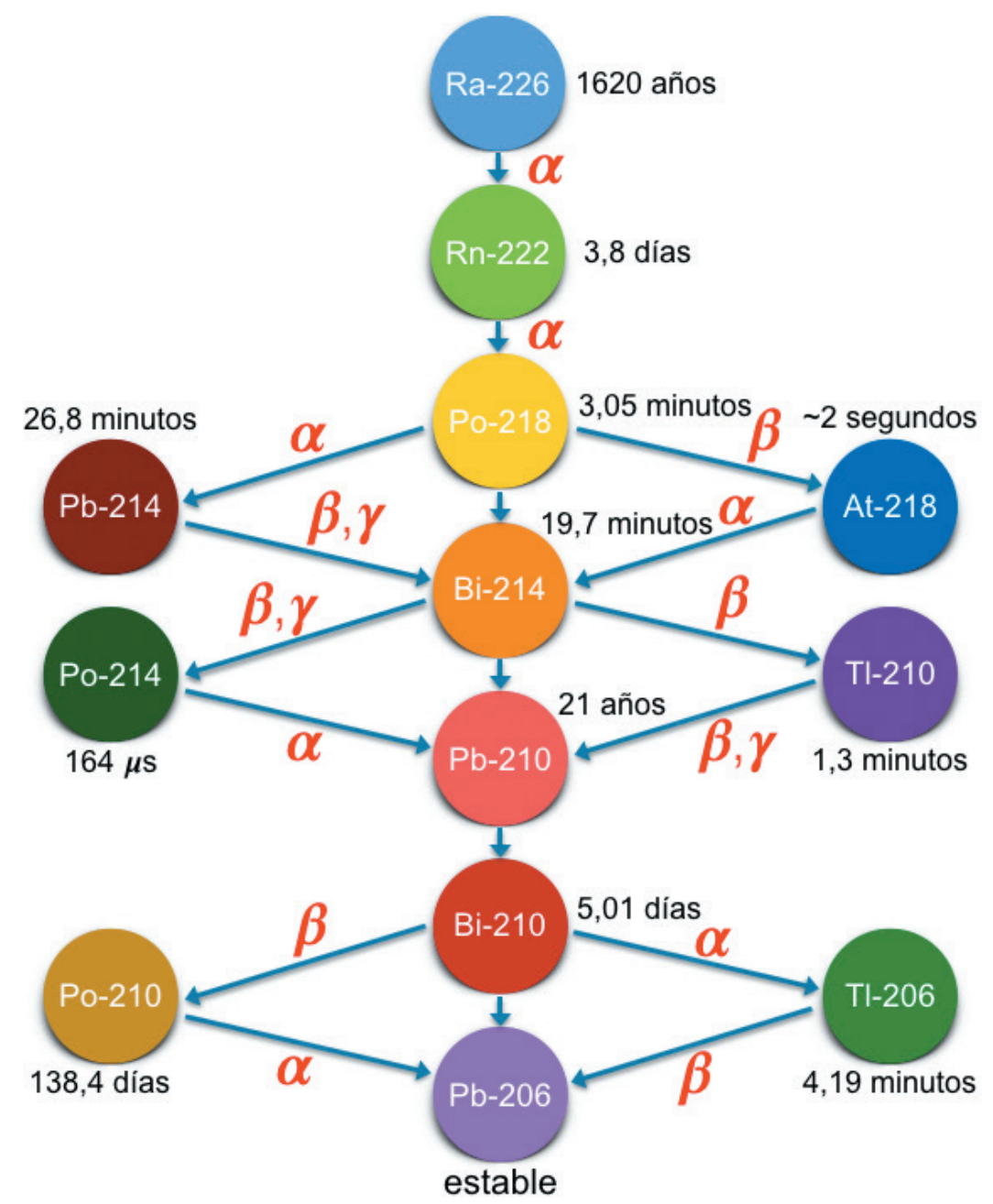

Cadena de desintegración del Radio-226. Se indica la vida media de cada isótopo y el tipo de radiación ionizante ( $\alpha$, $\beta, \gamma)$ emitida en su desintegración. 


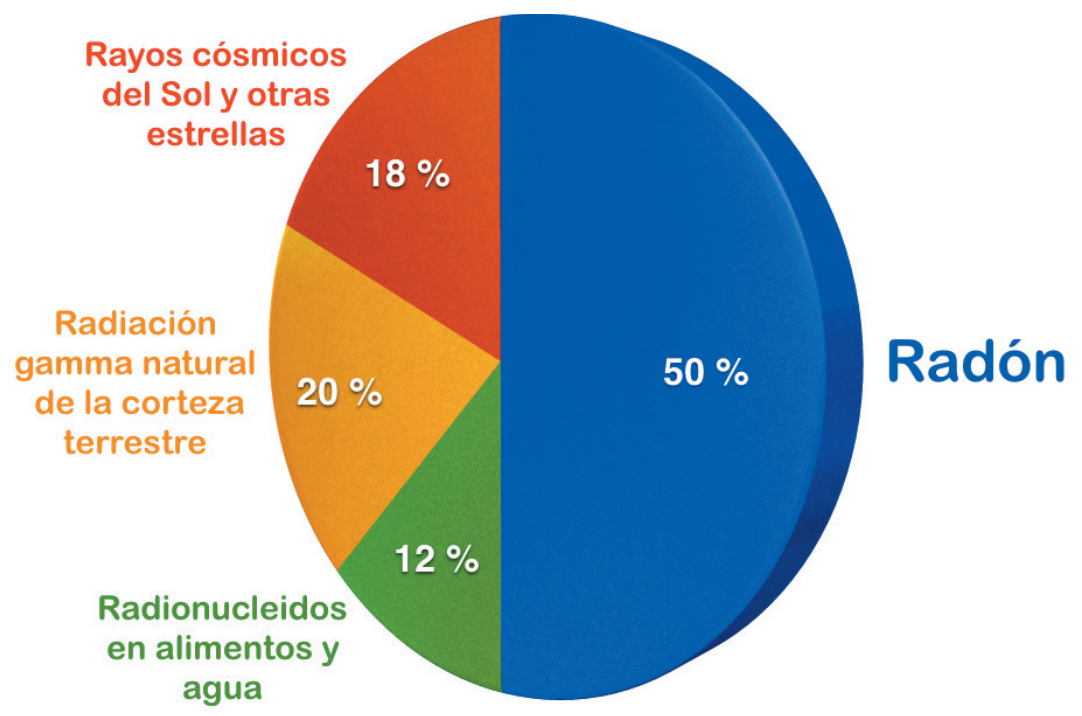

Radiación natural a la que está expuesta la población mundial. Fuente: UNSCEAR, 2000 (United Nations Scientific Committee on the Effects of Atomic Radiation).

\section{Efectos sobre la salud del gas radón}

La Organización Mundial de la Salud (OMS), a través de un grupo de trabajo europeo sobre la calidad del aire en interiores, en 1979 llamó por primera vez la atención acerca de los efectos para la salud de la exposición al radón. El radón fue clasificado como carcinógeno humano en 1988 por el CIIC, el organismo especializado de investigación oncológica de la OMS. En 1993, un taller internacional de la OMS sobre el radón en interiores, puso de manifiesto la necesidad de controlar la exposición de las personas al radón y de informar a la sociedad de los riesgos para la salud. La 


\section{MANUAL DE LA OMS SOBRE EL RADÓN EN INTERIORES}

\section{UNA PERSPECTIVA DE SALUD PÚBLICA}
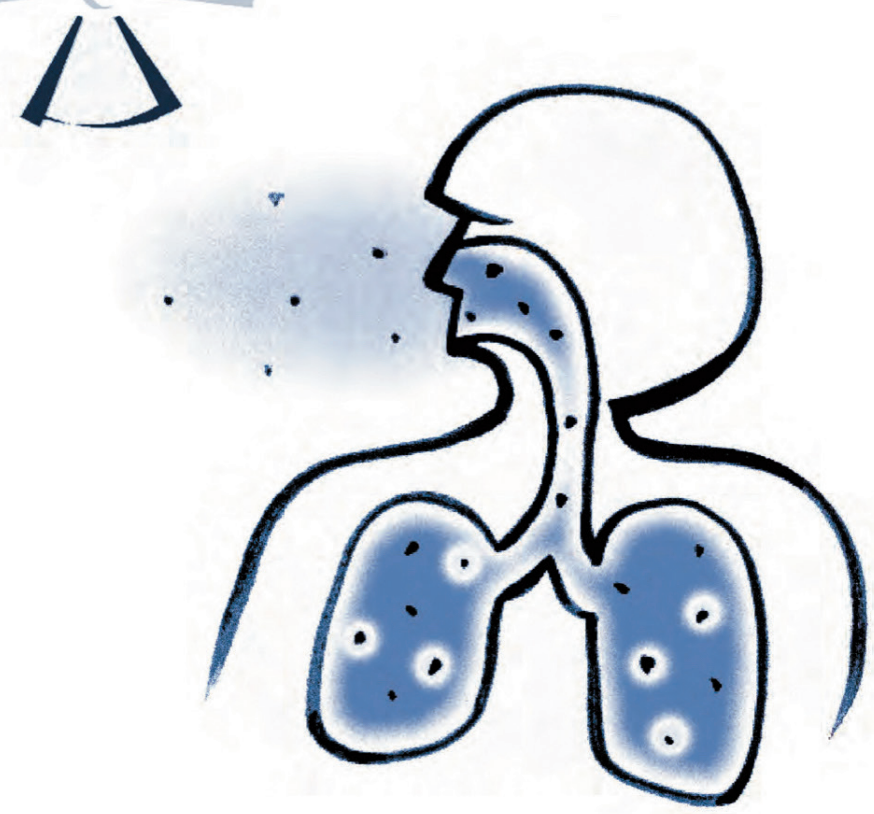

El «Manual de la OMS sobre el radón en interiores» es un documento de referencia cuya lectura es muy recomendable para los responsables de la salud pública. 
OMS ha publicado un manual sobre el radón en interiores, en el marco de su Proyecto Internacional del Radón, que contó con la participación y aportaciones de más de 100 expertos en la materia; este manual está publicado en varios idiomas, entre ellos el español, y es un documento de referencia que cualquier responsable de salud pública debería consultar.

La Agencia Internacional para la Investigación del Cáncer, IARC (International Agency for Research on Cancer), clasifica al radón como «carcinógeno para los humanos» del grupo 1, que es la categoría superior de las sustancias consideradas como sospechosas de causar cáncer. La IARC considera que todos los radionucleidos que emiten partículas alfa y que han sido estudiados en detalle, incluyendo al Rn-222 y sus descendientes, han demostrado que generan cáncer en humanos.

En cuanto al efecto que el radón produce sobre la salud de las personas, la naturaleza radiactiva del radón no implica en sí mismo un riesgo, ya que en la corteza terrestre hay multitud de elementos radiactivos que forman parte de los minerales que la conforman, y que en su mayoría se presentan en estado sólido; sin embargo, el hecho de que el radón sea un gas es su verdadero peligro, porque puede llegar hasta las personas por el aire e introducirse en el cuerpo por las vías respiratorias. Por tanto, el radón supone un riesgo potencial para la salud de las personas por la inhalación del mismo.

Pero para ser exactos, no es el radón en concreto el que va a provocar el daño a nuestro organismo, sino los productos atómicos que de él se generan en su desintegración radiactiva. Cuando inhalamos aire y el átomo gaseoso de 


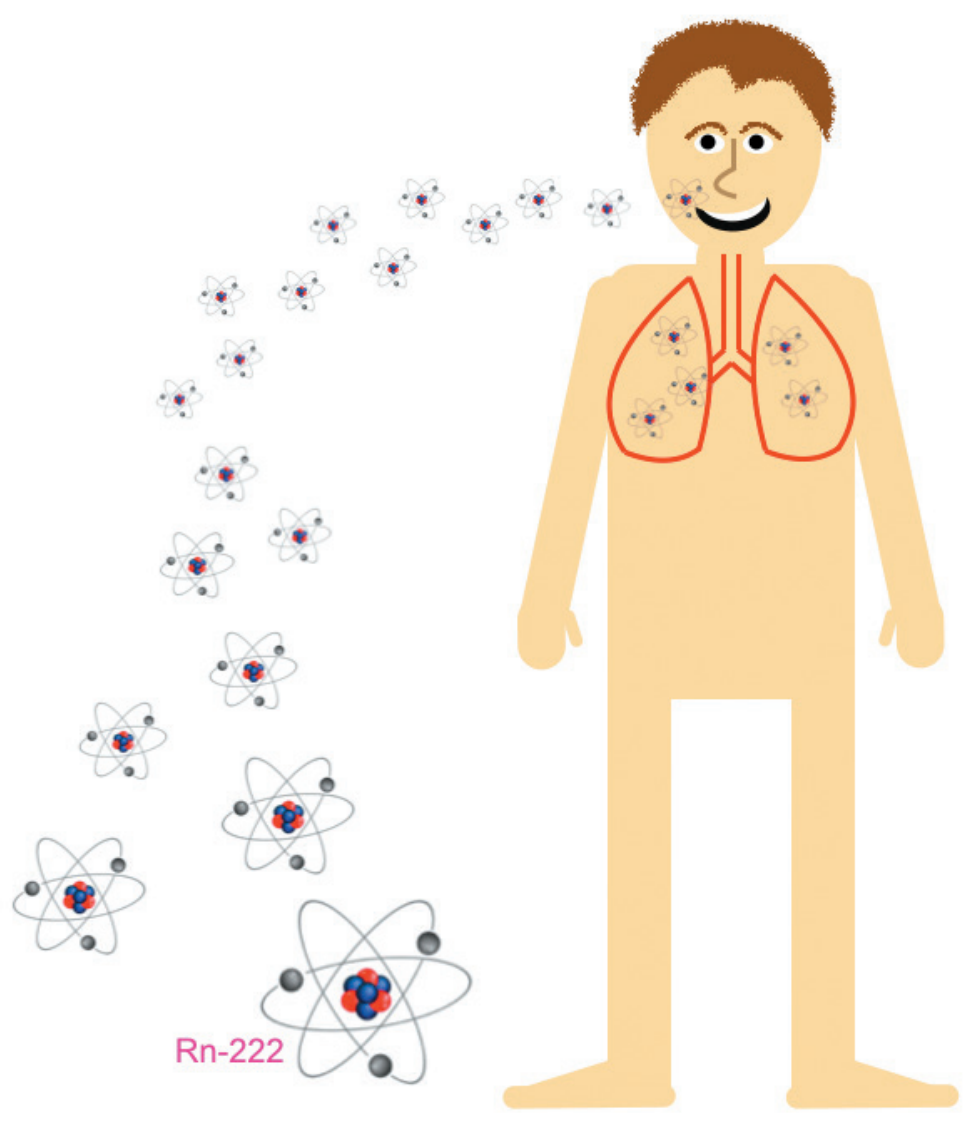

Los átomos de radón gaseosos exhalados por el terreno, se introducen en nuestras vías respiratorias cuando respiramos.

radón se introduce en nuestro cuerpo, sus descendientes que si son sólidos pueden adherirse al tracto respiratorio y las emisiones de partículas alfa de alta energía, que son emitidas en los procesos de desintegración de todos estos átomos, pueden entrar en contacto con los epitelios pulmonares, produciendo ionizaciones en el cuerpo de las células, dañando su ADN y volviéndolas cancerígenas. 


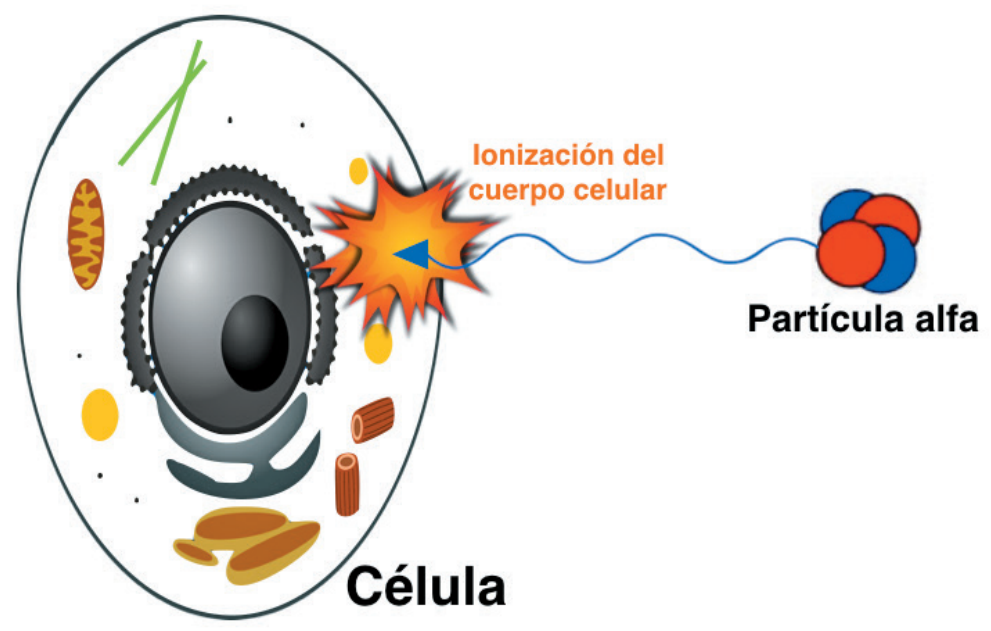

Las partículas alfa emitidas en la desintegración de isótopos radiactivos que respiramos pueden dañar el ADN de las células y volverlas cancerígenas.

El radón es un asesino silencioso, pues no se oye, no se ve, es insípido y no huele, y va dañando nuestro organismo poco a poco sin que nos demos cuenta.

Según la OMS, el radón es la segunda causa de cáncer de pulmón, después del tabaco; o lo que es lo mismo, la primera causa de cáncer de pulmón en no fumadores.

La Comisión Europea ha elaborado el Código Europeo contra el Cáncer, una iniciativa que tiene por objeto informar a los ciudadanos sobre lo que pueden hacer para reducir el riesgo de cáncer. Contiene 12 recomendaciones y la número 9 se refiere específicamente al control de la exposición al radón como una de las formas de reducir el riesgo de padecer cáncer. 


\section{CÓDIGO EUROPEO CONTRA EL CÁNCER}

\section{2 formas de reducir el riesgo de cáncer}

1 No fume. No consuma ningún tipo de tabaco.

2 Haga de su casa un hogar sin humo. Apoye las políticas antitabaco en su lugar de trabajo.

3 Mantenga un peso saludable.

4 Haga ejercicio a diario. Limite el tiempo que pasa sentado.

5 Coma saludablemente:

- Consuma gran cantidad de cereales integrales, legumbres, frutas y verduras.

- Limite los alimentos hipercalóricos (ricos en azúcar o grasa) y evite las bebidas azucaradas.

- Evite la carne procesada; limite el consumo de carne roja y de alimentos con mucha sal.

6 Limite el consumo de alcohol, aunque lo mejor para la prevención del cáncer es evitar las bebidas alcohólicas.

7 Evite una exposición excesiva al sol, sobre todo en niños. Utilice protección solar. No use cabinas de rayos UVA.

8 En el trabajo, protéjase de las sustancias cancerígenas cumpliendo las instrucciones de la normativa de protección de la salud y seguridad laboral.

9 Averigüe si está expuesto a la radiación procedente de altos niveles naturales de radón en su domicilio y tome medidas para reducirlos.

10 Para las mujeres:

- La lactancia materna reduce el riesgo de cáncer de la madre. Si puede, amamante a su bebé.

- La terapia hormonal sustitutiva (THS) aumenta el riesgo de determinados tipos de cáncer. Limite el tratamiento con THS.

11 Asegúrese de que sus hijos participan en programas de vacunación contra:

- la hepatitis B (los recién nacidos)

- el virus del papiloma humano (VPH) (las niñas).

12 Participe en programas organizados de cribado del cáncer:

- colorrectal (hombres y mujeres)

- de mama (mujeres)

- cervicouterino (mujeres).

El Código Europeo contra el Cáncer se centra en medidas que cada ciudadano puede tomar para contribuir a prevenir el cáncer. El éxito de la prevención del cáncer exige que las políticas y acciones gubernamentales apoyen estas acciones individuales.

Para saber más sobre el Código Europeo contra el Cáncer, consulte la página: http://cancercode-europe.iarc.fr

International Agency for Research on Cancer

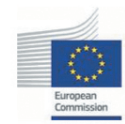

Código Europeo Contra el Cáncer. Fuente: Comisión Europea. 
El Ministerio de Trabajo y Asuntos Sociales del Gobierno de España, reconoce como causa de enfermedad profesional al radón, indicando que es el causante de neoplasia maligna de bronquio y pulmón (Real Decreto 1299/2006, de 10 de noviembre).

\section{Normativa de aplicación en materia de seguridad laboral}

En la actualidad, los titulares de los centros de trabajo deben cumplir con el Real Decreto 1439/2010, de 5 de noviembre, por el que se modifica el Reglamento sobre protección sanitaria contra radiaciones ionizantes, aprobado por Real Decreto 783/2001, de 6 de julio (BOE núm. 279, de 18.11.2010). Este Real Decreto obliga directamente a los titulares de las actividades en las que existan fuentes naturales de radiación a realizar los estudios necesarios para determinar si existe un incremento significativo de la exposición de los trabajadores o de los miembros del público, que no pueda considerarse despreciable desde el punto de vista de la protección radiológica, sin necesidad de que estos estudios sean exigidos por las autoridades competentes. Además, se debe declarar estas actividades ante los órganos competentes en materia de industria de las Comunidades Autónomas en cuyo territorio se realizan estas actividades laborales. En Canarias, esta competencia recae actualmente en la Consejería de Economía, Industria, Comercio y Conocimiento. 
Entre las actividades que deben ser declaradas y sometidas a dichos estudios se incluyen las siguientes: Actividades laborales en las que los trabajadores y, en su caso, los miembros del público estén expuestos a la inhalación de descendientes de torón o de radón o a la radiación gamma o a cualquier otra exposición en lugares de trabajo tales como establecimientos termales, cuevas, minas, lugares de trabajo subterráneos o no subterráneos en áreas identificadas. Establece también que la declaración de actividades y los estudios a los que se refiere se realizarán siguiendo las instrucciones y orientaciones dadas por el Consejo de Seguridad Nuclear.

Así pues, el Consejo de Seguridad Nuclear, como responsable en la materia, publica la Instrucción IS-33, de 21 de diciembre de 2011, del Consejo de Seguridad Nuclear, sobre criterios radiológicos para la protección frente a la exposición a la radiación natural (BOE núm. 22, de 26.01.2012). Dicha instrucción establece que el nivel para la protección de los trabajadores frente a la exposición al Radón en sus puestos de trabajo debe ser de $600 \mathrm{~Bq} / \mathrm{m}^{3}$ de concentración media anual de radón, durante la jornada laboral.

La Unión Europea, por su parte, dicta por primera vez en 1959 normas básicas, mediante las Directivas de 2 de febrero de 1959, relativas a la protección sanitaria de la población y los trabajadores y contra los peligros que resultan de las radiaciones ionizantes. A partir de aquí se suceden distintas directivas hasta la vigente actualmente, la Directiva 2013/59/EURATOM del Consejo de 5 de diciembre de 2013, por la que se establecen normas de seguridad básicas para la protección contra los peligros derivados de la exposición 
a radiaciones ionizantes. La norma indica que cuando el radón penetre desde el terreno en los recintos cerrados de trabajo, debe considerarse como una situación de exposición existente, dado que la presencia del radón es en gran medida independiente de las actividades humanas realizadas dentro del lugar de trabajo. Tales exposiciones pueden ser significativas en determinadas zonas o en tipos específicos de lugares de trabajo que corresponde determinar a los Estados miembros, y, en caso de superarse el nivel de referencia nacional, se deben tomar las medidas adecuadas de reducción del radón y de la exposición. Si los niveles continúan siendo superiores al nivel de referencia nacional, esas actividades humanas realizadas dentro del lugar de trabajo no deben considerarse como prácticas. No obstante, los Estados miembros deben velar por que se notifiquen esos lugares de trabajo y porque, en los casos en que la exposición de los trabajadores pueda superar un valor correspondiente de exposición al radón integrada en el tiempo, dichos lugares se gestionen como una situación de exposición planificada, se apliquen límites de dosis, y deben determinar los requisitos de protección operacional que hayan de aplicarse. Entre los lugares de trabajo que requieren medidas de radón se encuentran los edificios con acceso público, por ejemplo, escuelas, lugares de trabajo subterráneos o los situados en determinadas zonas, como las volcánicas.

Los Estados miembros de la UE establecerán un plan de acción a nivel nacional para hacer frente a los riesgos a largo plazo debidos a las exposiciones al radón en viviendas, edificios de acceso público y lugares de trabajo para cualquier vía de entrada del radón, ya sea el suelo, los materiales de construcción o el agua. 


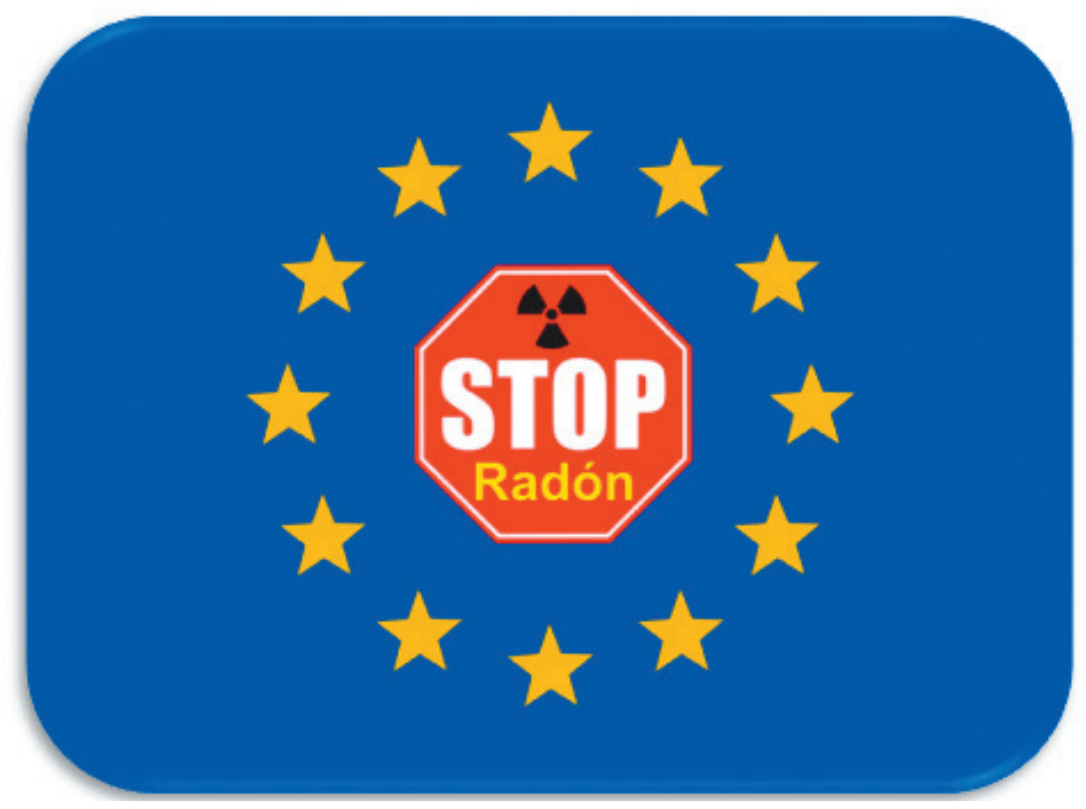

La Unión Europea planta cara al radón y obliga a los países miembros a establecer planes nacionales de acción contra el mismo a través de la directiva EURATOM.

La directiva europea establece como nivel de referencia de las concentraciones de radón en recintos cerrados, tanto de viviendas como en los lugares de trabajo, $300 \mathrm{~Bq} / \mathrm{m}^{3}$. Este valor no debe superarse. El Gobierno de España trabaja actualmente en la modificación del Real Decreto 1439/2010, para adaptarlo a la directiva europea y rebajar los valores de referencia de concentración de radón a los $300 \mathrm{~Bq} / \mathrm{m}^{3}$.

La directiva EURATOM, publicada en el Diario Oficial de la Unión Europea el 17 de enero de 2014, establece que los Estados miembros pondrán en vigor las disposiciones legales, reglamentarias y administrativas necesarias para dar 
cumplimiento a lo establecido en la presente Directiva a más tardar el 6 de febrero de 2018.

La OMS advierte de la importancia de determinar si nuestro lugar de trabajo se encuentra expuesto a concentraciones de radón que superen los límites recomendados por los organismos públicos de salud.

\section{El radón en lugares de trabajo de Canarias}

Las islas Canarias son un archipiélago de naturaleza volcánica en el que se encuentran representadas la mayoría de las rocas volcánicas existentes en nuestro planeta. La variedad de formaciones, productos y litologías volcánicas presentes en las Islas Canarias, hacen que sean consideradas como uno de los territorios del mundo más interesantes desde el punto de vista vulcanológico.

Como se ha dicho, el radón procede de la cadena de desintegración del uranio y a su vez este procede de las rocas de la corteza terrestre. Por tanto, las rocas con mayor contenido en uranio serán las que pueden exhalar mayor cantidad de radón. Es sabido que el uranio primigenio de las rocas de la corteza proviene mayoritariamente de los magmas félsicos o ácidos, que son aquellos que se caracterizan por su alto contenido en sílice. Cuando estos magmas enfrían en el interior de la corteza a grandes profundidades dan lugar a rocas plutónicas como los granitos; si el magma logra salir al exterior dará lugar a rocas volcánicas como las 
riolitas. El caso opuesto a los magmas félsicos son los magmas máficos o básicos, que, con menor contenido en uranio y sílice, dan lugar a rocas volcánicas como los basaltos. En medio de ambos magmas hay otros que se denominan intermedios, que dan lugar a rocas volcánicas como traquitas y fonolitas, cuyo contenido en uranio es moderado. En las islas Canarias se puede encontrar un amplio espectro de rocas volcánicas, desde basaltos a riolitas, pasando por traquitas y fonolitas, lo que significa que existen rocas con contenidos significativos de uranio.

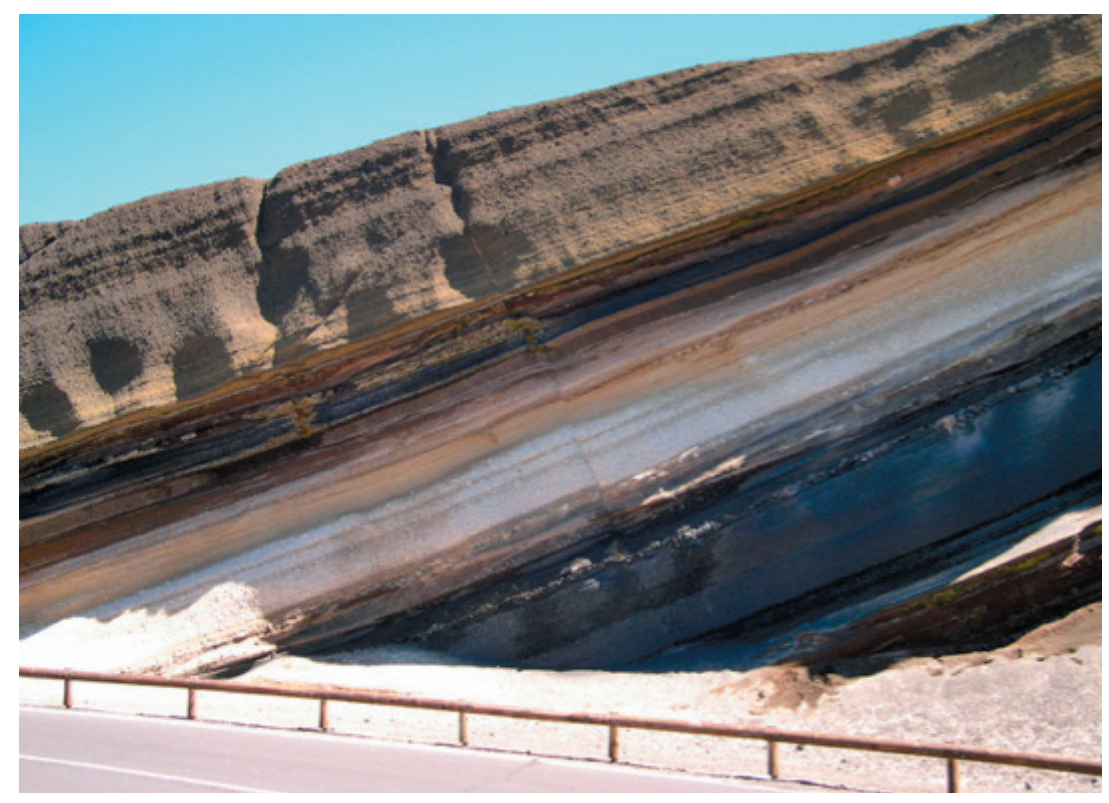

Alternancia de piroclastos sálicos (color claro) y básicos (color oscuro). Los piroclastos se caracterizan por su elevada porosidad, que facilita la exhalación del gas radón.

El Consejo de Seguridad Nuclear, en su Guía de Seguridad 11.04, indica que existen zonas del país donde la población 
se encuentra potencialmente expuesta a un riesgo significativo de inhalación de radón y de sus descendientes de vida corta. Estas zonas las denomina "áreas identificadas» y se corresponden con aquellas cuya geología pueda generar o favorecer el transporte al interior de lugares cerrados de grandes cantidades de radón, tales como zonas graníticas, zonas volcánicas o zonas de fallas activas. Por este motivo, las Islas Canarias, de origen volcánico, requieren de una especial atención y en los mapas del CSN figuran como una región con zonas de mayor exposición potencial al radón.

Son varios los factores que influyen en la mayor o menor concentración de gas radón en el interior de los lugares de trabajo:

- La geología de la zona donde se localiza el lugar de trabajo.

- La permeabilidad del terreno. Juega un papel importante y es bien sabido que los terrenos canarios, dada su naturaleza volcánica, son altamente porosos y permeables, por lo que facilitan el ascenso del gas radón hacia la superficie.

- La calidad de las construcciones. Contribuye notablemente a la presencia de radón en el interior de los recintos, ya que la inexistencia o deficiencia de aislamiento entre el terreno y la estructura permite el paso de este gas. Los edificios antiguos son los más vulnerables frente al radón, debido a que suelen tener carencias importantes en cuanto a la impermeabilización de la superficie de cimentación, además de presentar fisuras o discontinuidades por las que se cuela el gas proveniente del subsuelo. 
- La disposición respecto al terreno en la que se encuentra el lugar de trabajo, ya que son más peligrosos los espacios subterráneos, como locales en sótanos o aparcamientos públicos.

- Especial atención requieren los lugares de trabajo subterráneos excavados en el terreno de naturaleza volcánica y generalmente con deficiente ventilación, como son las cuevas turísticas y las minas o galerías de agua, muy abundantes en Canarias para el aprovechamiento de los recursos hídricos. En este tipo de lugares las concentraciones de gas radón pueden superar ampliamente los valores límite establecidos en la normativa vigente.

- Los materiales de construcción. Aunque en menor medida que la geología, algunos materiales de construcción pueden contribuir a incrementar las concentraciones de radón en interiores si han sido elaborados con materias primas de naturaleza volcánica (áridos, cementos). En Canarias se fabrican cementos puzolánicos; la puzolana empleada no es otra cosa que rocas piroclásticas sálicas (traquitas, fonolitas, riolitas) molidas finamente.

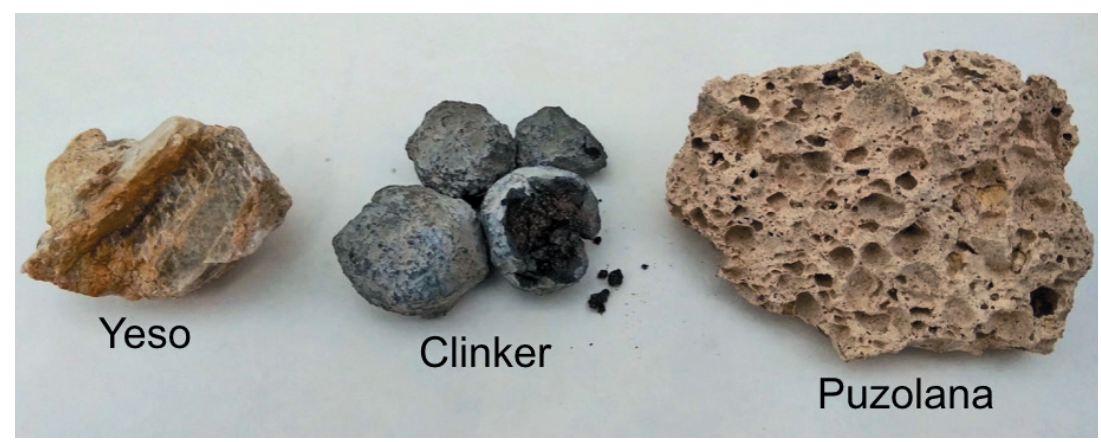

\section{Componentes del cemento puzolánico.}


- El agua. El radón pasa de las rocas al agua, porque es soluble en ella, pero puede pasar de nuevo fácilmente al aire. Si las aguas de suministro son superficiales (ríos, lagos) el radón se libera a la atmósfera, pero si las aguas son subterráneas, se explotan con galerías o pozos (como ocurre en Canarias) y luego se conducen a través de tuberías, el radón puede llegar en el agua hasta nuestras viviendas o lugares de trabajo y luego es liberado al aire cuando abrimos el grifo. De ahí la importancia de controlar el radón en los lugares de trabajo interiores en los que se haga tratamiento del agua (depuradoras, balnearios, spas, piscinas cubiertas, etc).

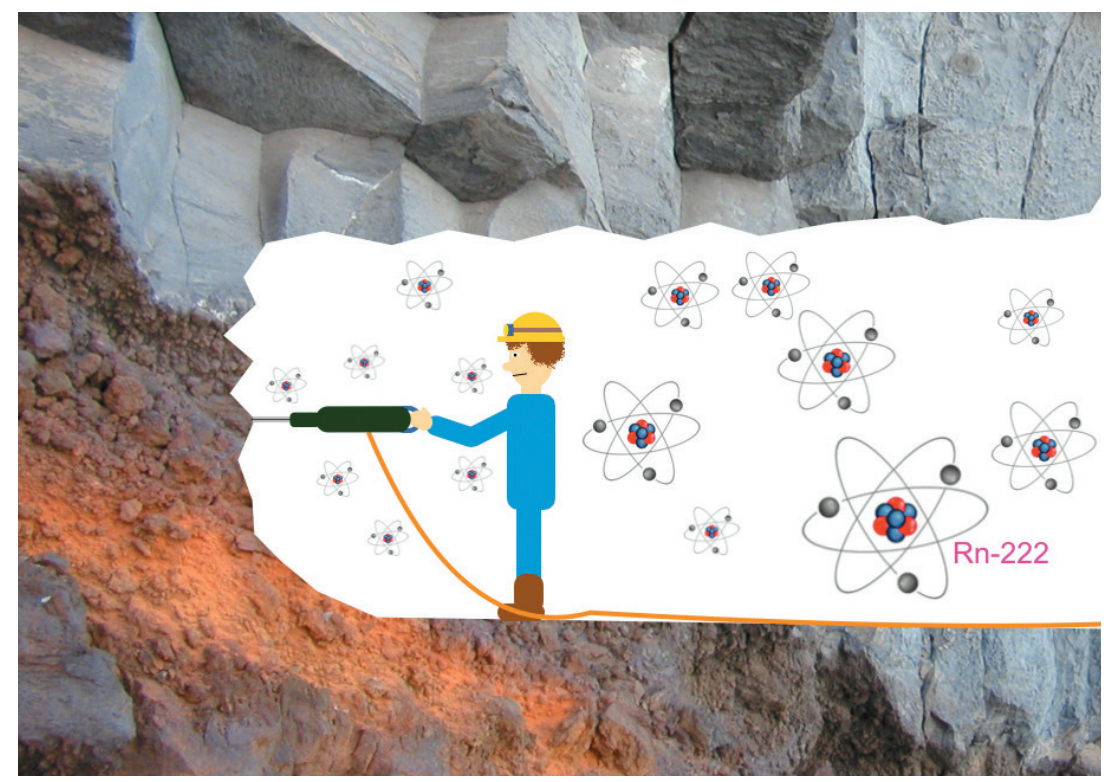

Los trabajos subterráneos en terrenos volcánicos, como galerías o pozos, requieren de un especial control de la concentración de gas radón pues los valores esperados son muy elevados. 


\section{Sistemas de medida de concentración de radón}

Los sistemas de medida de la concentración de gas radón en interiores se clasifican generalmente en activos y pasivos:

- Los sistemas de medida activos ofrecen una medida instantánea que se produce a partir de la generación de una señal eléctrica al detectar la radiación ionizante; requieren de una fuente de energía eléctrica para su funcionamiento, bien a través de baterías o por conexión a la red eléctrica.
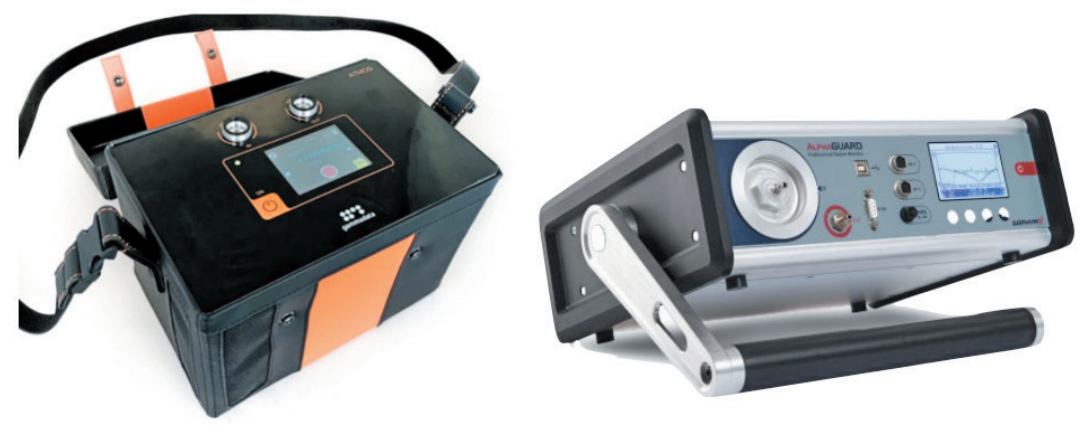

Equipos de medida activos de la concentración de gas radón.

- Los sistemas de medida pasivos no requieren de una fuente eléctrica, la radiación interacciona con el detector de forma continua durante un periodo de exposición preestablecido, en el que impresionan o impregnan un material (película, gránulos, etc.) que luego es revelado o analizado en un laboratorio; es el método de medida re- 
comendado por la OMS, ya que permiten la lectura en un periodo largo de tiempo (3 meses) y dan información sobre la concentración media de radón a la que los trabajadores están expuestos.

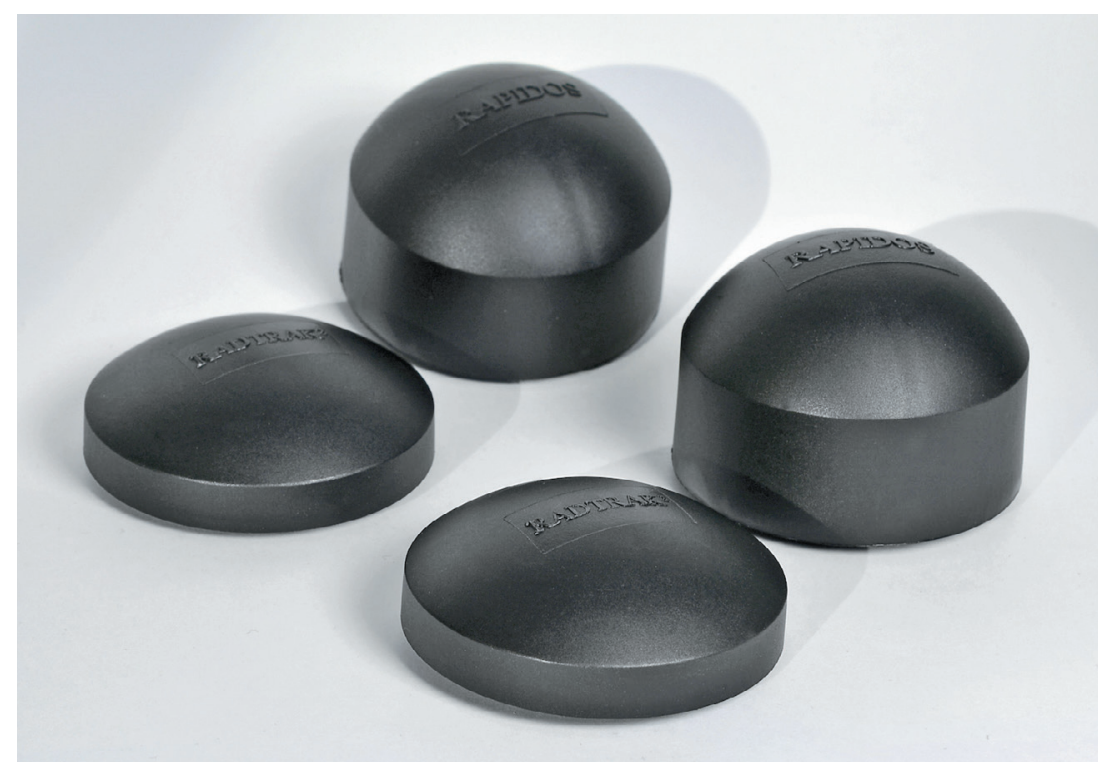

\section{Detectores pasivos de trazas nucleares.}

También se pueden clasificar los sistemas de medida, atendiendo al tiempo que se emplea en realizar la medida, en sistemas de medida integrada, en continuo y puntuales:

- En los sistemas de medida integrada, la medida se realiza durante un periodo de tiempo prolongado que normalmente va de unos días a varios meses, recomendándose habitualmente que sean 3 meses; el valor ofrecido es la media de la concentración de radón registrada en el periodo de medida. 
- Los sistemas de medida en continuo permiten disponer de medidas en intervalos de tiempo cortos (minutos, horas) a lo largo de un periodo de medida que puede ir de unas horas, a días, semanas o meses. Los sistemas de medida puntuales ofrecen una medida instantánea de forma puntual, aunque requieren de un corto tiempo de exposición del equipo (generalmente menos de 2 horas).

Los detectores pasivos de trazas nucleares de última generación son los más usados en la medida de radón en interiores. Consisten en una película sensible a la radiación ubicada dentro de una cápsula hecha de un plástico antiestático especial que permite la entrada del gas radón por difusión. Estos detectores son inocuos y no interfieren con las personas. No requieren de fuente de alimentación y realizan una medida integrada por un periodo recomendado de 3 meses. Pueden ser instalados por el propio cliente, siguiendo unas recomendaciones básicas y sencillas. Transcurrido el periodo de exposición y medida, se retiran y envían a un laboratorio que, mediante un escáner de imágenes de última generación, analiza los detectores y emite un informe con el resultado. Para ofrecer las máximas garantías en las medidas, el Consejo de Seguridad Nuclear (CSN) recomienda que estos laboratorios estén acreditados de acuerdo con la norma ISO/IEC 17025. EI CSN en su página web recoge un listado con los laboratorios que cumplen con este requisito. 


\section{Procedimiento de evaluación de la exposición al radón en lugares de trabajo}

El procedimiento aquí descrito es de aplicación a los lugares de trabajo interiores radicados en las islas Canarias, siendo de aplicación tanto a las actividades que desarroIlen trabajadores por cuenta ajena como por cuenta propia y tanto del ámbito privado como del sector público.

Se excluyen los lugares de trabajo cuya actividad laboral se desarrolle al aire libre.

Este procedimiento se corresponde con la metodología desarrollada por el Consejo de Seguridad Nuclear (CSN) en su Guía de Seguridad 11.4 Metodología para la evaluación de la exposición al radón en los lugares de trabajo y da cumplimiento del Real Decreto 1439/2010, de 5 de noviembre, por el que se modifica el Reglamento sobre protección sanitaria contra radiaciones ionizantes, aprobado por Real Decreto 783/2001, de 6 de julio (BOE núm. 279, de 18.11.2010). Dicha guía se concibió como orientación para la aplicación del Reglamento sobre Protección Sanitaria contra Radiaciones lonizantes (RPSRI). La guía es el documento oficial de aplicación para estudiar el radón en los lugares de trabajo y la metodología propuesta en el presente documento ayuda, actualiza y complementa algunos aspectos para su aplicación en Canarias.

El CSN indica que los lugares de trabajo situados en «áreas identificadas», como las zonas volcánicas, requieren de los 
estudios de evaluación de la exposición al radón que prescribe el Real Decreto 1439/2010, de 5 de noviembre. Por tanto, este Real Decreto es de obligada aplicación en toda la Comunidad Autónoma de Canarias, ya que el archipiélago es en su totalidad de naturaleza volcánica.

El RPSRI establece que los titulares de las actividades laborales, en las que existan fuentes naturales de radiación, deberán declarar estas actividades ante los órganos competentes en materia de industria de las Comunidades Autónomas en cuyo territorio se realizan estas actividades laborales y realizar los estudios necesarios a fin de determinar si existe un incremento significativo de la exposición de los trabajadores o de los miembros del público que no pueda considerarse despreciable desde el punto de vista de la protección radiológica. En Canarias el órgano competente es la Consejería de Economía, Industria, Comercio y Conocimiento, responsable de disponer y mantener un «Registro de actividades laborales con exposición a la radiación natural», conforme a lo dispuesto en el Real Decreto 1439/2010, de 5 de noviembre.

Las fases en las que se estructura este estudio son las que indica la Guía de Seguridad 11.4, y son las siguientes:

- Planificación del estudio.

- Realización de las exposiciones y análisis de los dispositivos de medida.

- Expresión de los resultados y toma de decisiones.

- Diseño e implantación, si procede, de medidas para reducir las exposiciones al radón de los trabajadores y del público. 


\subsection{Planificación del estudio}

Las mediciones deben realizarse en lugares que sean representativos de la ocupación real o razonablemente previsible de los trabajadores. Por esta razón, no será necesario realizar mediciones en áreas tales como pasillos, baños, etc. que estén desocupados o que estén ocupados con poca frecuencia. Se puede considerar que un área poco ocupada es aquella en la que es poco probable que una persona pase más de 100 horas al año de su tiempo de trabajo (aproximadamente dos horas por semana).

Se medirá siempre en recintos subterráneos o de sótano y otros recintos o salas, donde existe un riesgo significativo de entrada importante de radón (por ej. instalaciones de tratamiento de aguas), que las personas podrían usar durante más de 50 horas por año (aproximadamente una hora por semana).

El número de puntos de medida, donde se colocarán los detectores, por lugar de trabajo, va a depender de factores como: Número de recintos en los que está compartimentado la instalación; las dimensiones de los recintos; el número de personas que realizan su actividad en el recinto; los tiempos de permanencia en el mismo; el número de zonas homogéneas de concentración de radón; y las características del lugar de trabajo.

Se denomina zona homogénea a los recintos en los que la concentración de radón en todo su volumen es homogénea o poco variable. Esta circunstancia está condicionada por la tipología de la construcción, el régimen de ventila- 
ción, la geología de la zona, las variables ambientales y los hábitos de los trabajadores.

Como mínimo se deberán seleccionar dos puntos de medida por lugar de trabajo.

Cuando sea posible, se recomienda realizar previamente una campaña de medida con sistemas de medida en continuo, de corta duración (uno o varios días), con el fin de localizar focos de radón, confirmar las zonas homogéneas y hacer una estimación inicial de las concentraciones que pueden esperarse.

Según la Guía de Seguridad 11.4, los estudios del riesgo radiológico ligado al radón deben ser representativos de la exposición anual de los trabajadores y, en su caso, del público. Para ello, los resultados deben basarse en medidas con detectores pasivos expuestos durante un periodo mínimo de tres meses.

Con toda esta información previa se procederá a determinar el número de detectores pasivos a instalar y así como la ubicación de los mismos. Tomando como base la Guía de Seguridad 11.4 del CSN, la Guía IRMA 0791-30 (International Radon Measurement Asosociation, IRMA 2017) y la Guía RPII (Radiological Protection Institute of Ireland, RPII, 2013), se ha elaborado la Tabla 1 de densidad de detectores pasivos para lugares de trabajo no subterráneos. 


\section{Tabla 1. Densidad de detectores pasivos para lugares de trabajo no subterráneos.}

Oficinas compartimentadas en recintos de menos de $150 \mathrm{~m}^{2}$

Un detector por recinto

Áreas de hasta $1.000 \mathrm{~m}^{2}$ (oficinas de planta abierta, superficies de atención al público, al- Un detector por cada 150 m² macenes...) en planta baja, en contacto con el terreno.

Áreas de hasta $1.000 \mathrm{~m}^{2}$ (oficinas de planta abierta, superficies de atención al público, al- Un detector por cada 250 m² macenes...) en primera planta o superiores.

Áreas de hasta $5.000 \mathrm{~m} 2$, en planta baja, en contacto con el Un detector por cada $400 \mathrm{~m}^{2}$ terreno. Áreas de hasta $5.000 \mathrm{~m} 2$, en Un detector por cada $500 \mathrm{~m}^{2}$
primera planta o superiores.

Áreas muy extensas (varios miles de $\mathrm{m}^{2}$ ), en planta baja, en Un detector por cada $500 \mathrm{~m}^{2}$ contacto con el terreno.

Áreas muy extensas (varios miles de $\mathrm{m}^{2}$ ), en primera planta o Un detector por cada $750 \mathrm{~m}^{2}$ superiores.

Sótanos

Un detector por recinto 
El periodo de exposición de los detectores será de al menos de tres meses, evitando el periodo estival (entendido como el intervalo que comprende los meses de junio a septiembre), excepto para instalaciones que permanezcan cerradas durante el otoño-invierno.

En lugares de trabajo subterráneos se recomienda que las exposiciones abarquen un año completo. Las medidas se deberían realizar en cuatro periodos consecutivos de tres meses de duración cada uno.

En cavidades subterráneas como las cuevas turísticas, dadas las marcadas variaciones estacionales que se han descrito en algunas cuevas, se recomienda que cuando el promedio anual sea elevado se lleven a cabo caracterizaciones mes a mes. La localización y número de detectores pasivos dependerá del número de puntos en el trazado de la cueva en los que hay presencia humana, dando prioridad a los puntos donde pueda haber personas que, durante periodos de tiempo considerables, desarrollen su actividad profesional (guías, espeleólogos, arqueólogos...).

\subsection{Realización de las exposiciones y análisis de los dispositivos de medida}

Las exposiciones seguirán las indicaciones del CSN en su Guía de Seguridad 11.01 Directrices sobre la competencia de los laboratorios y servicios de medida de radón en aire.

El laboratorio que realice las medidas deberá estar acreditado de acuerdo con la Norma ISO/IEC 17025. El titular de 
la actividad laboral asumirá la responsabilidad de verificar que el laboratorio de medida cuente con una acreditación en vigor.

En la colocación de los detectores pasivos se han de tener en cuenta las siguientes indicaciones:

a) Ubicación de detectores

- Se deben situar a una altura no inferior a $50 \mathrm{~cm}$ sobre nivel del suelo.

- Se deben situar a una distancia de más de $30 \mathrm{~cm}$ de paredes exteriores y $10 \mathrm{~cm}$ de otros objetos y nunca dentro de armarios u otro tipo de objetos.

- No deben colocarse próximos a corrientes de aire (ventanas, ventiladores, etc.), ni exponerse directamente al sol u otras fuentes de calor (radiadores, televisores, otros aparatos eléctricos).

- Deben evitarse aquellos lugares donde la humedad pueda ser elevada, como cocinas, lavaderos o cuartos de baño.

- Deben situarse fuera del alcance de niños y animales domésticos.

b) Instalación de detectores

El detector pasivo se suministra dentro de una bolsa hermética o con algún precinto que no se debe abrir o retirar hasta el momento de la instalación. 


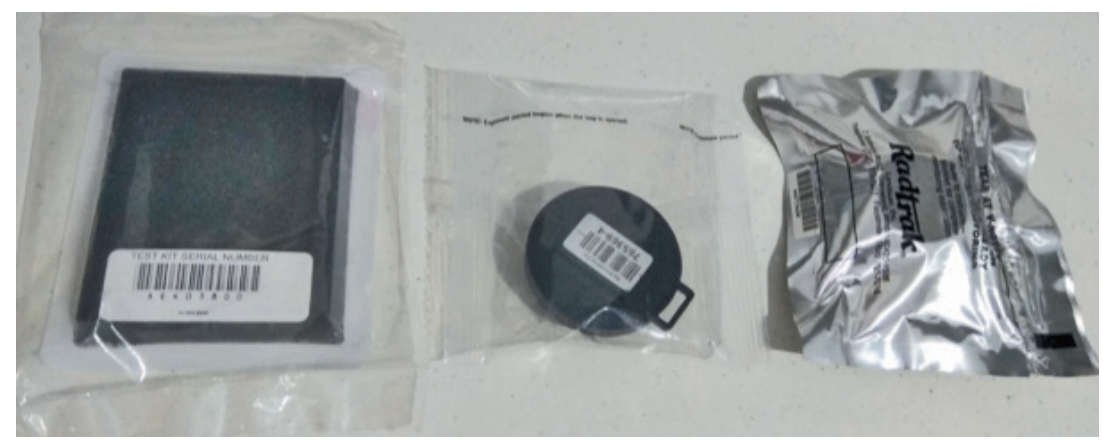

Detectores pasivos en sus recipientes herméticos antes de ser utilizados.

Para la instalación de detectores pasivos se recomienda seguir los siguientes pasos:

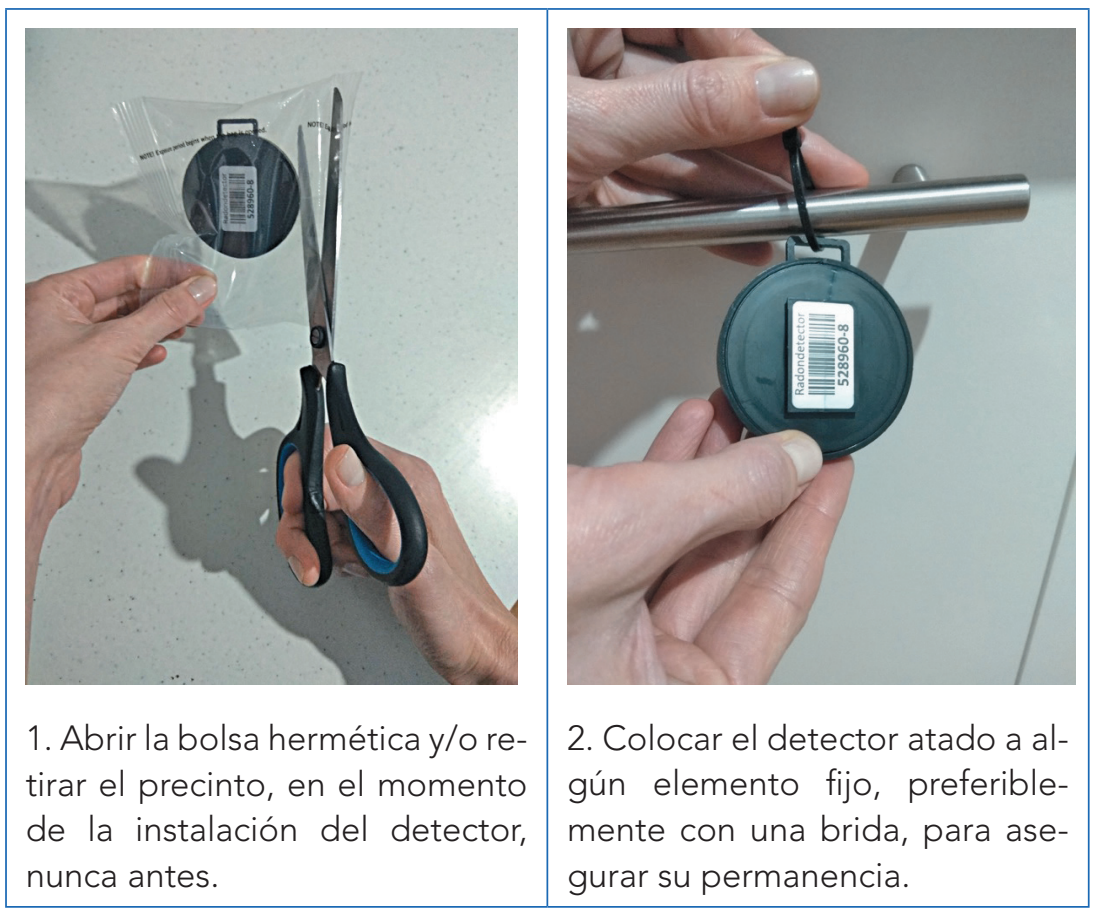


Se debe obtener y registrar la siguiente información en la instalación de cada detector:

- Fecha y hora de la instalación.

- Descripción del lugar de trabajo.

- Dirección completa del lugar de medida (dirección postal y/o coordenadas geográficas).

- Dimensiones del recinto.

- Esquema gráfico indicando ubicación de detectores.

- Nivel o planta del edificio (sótano, planta baja, primera planta, etc.)

- Número de trabajadores en el recinto.

- Tiempo de permanencia diaria (en horas) de los trabajadores en el recinto.

- Número de detector (ID).

- Marca, modelo y laboratorio acreditado encargado del análisis del detector.

- Fotografía de detalle del detector en la que se visualice su número de identificación.

- Fotografía general del recinto en el que se visualice la zona de ubicación del detector.

- Cualquier incidencia observada durante la instalación del detector (sistema de calefacción, presencia de humidificadores, hábitos de los trabajadores, etc.). 
c) Retirada de los detectores.

Transcurridos 3 meses desde su instalación, se procederá a la retirada de los detectores, su empaquetado y envío en el menor tiempo posible al laboratorio acreditado para su análisis.

\subsection{Presentación e interpretación de resultados}

El laboratorio que analice los detectores deberá emitir un informe con el siguiente contenido:

- Nombre y dirección del laboratorio de medida.

- Nombre y dirección del cliente.

- Identificación del sistema de medida.

- Cualquier otra información relevante para la interpretación de los resultados o requerida por el cliente.

- El informe de resultados debe estar firmado por la persona o personas que aceptan la responsabilidad técnica del informe de medida, y en él constará su fecha de emisión.

- Los valores medidos expresados como concentraciones medias de Rn-222 en Bequerelios por metro cúbico $\left(\mathrm{Bq} / \mathrm{m}^{3}\right)$ durante el periodo de medida, junto con el valor de la incertidumbre.

- Datos de localización del detector en el lugar de trabajo.

- Indicación de la acreditación de acuerdo con la Norma ISO/IEC 17025. 


\subsection{Informe final}

Los resultados del estudio se recogerán en un informe final de carácter técnico, que debe contener, además de los resultados de las determinaciones de radón, un resumen con las conclusiones más importantes. El informe debe estar fechado y firmado por la persona responsable de su elaboración.

Este informe estará a disposición del trabajador, de las autoridades sanitarias, de la Inspección de Trabajo y Seguridad Social, y del Consejo de Seguridad Nuclear.

El informe deberá incluir toda la información indicada en los apartados anteriores de este procedimiento, que como mínimo será la siguiente:

1. Localización y descripción del lugar de trabajo.

2. Medidas de concentración de radón realizadas: resultados con indicación del método de medida, periodo de exposición, planos que indiquen la situación de los equipos de medida utilizados, información sobre los laboratorios que han participado en estas medidas y cualquier otra información relevante a la hora de interpretar los resultados obtenidos.

3. Descripción de los puestos de trabajo y tiempos de permanencia de los trabajadores en ellos.

4. Recomendaciones de acciones correctoras previstas 0 adoptadas cuando los resultados de las medidas estén por encima de los niveles de referencia. 


\subsection{Declaración de las actividades y los estudios ante el órgano competente de la Comunidad Autónoma de Canarias}

El informe final que recoge los datos de las actividades y los resultados del estudio de exposición al radón de los trabajadores, se debe remitir al órgano competente en materia de industria de la Comunidad Autónoma de Canarias, que es la Consejería de Economía, Industria, Comercio y Conocimiento, para su inclusión en el registro

Corresponde a los titulares de las actividades laborales, en las que existan fuentes naturales de radiación, declarar estas actividades ante el órgano competente, según establece el Real Decreto 1439/2010, de 5 de noviembre, por el que se modifica el Reglamento sobre protección sanitaria contra radiaciones ionizantes, aprobado por Real Decreto 783/2001, de 6 de julio (BOE núm. 279, de 18.11.2010).

\subsection{Protocolo de actuación cuando se superen los niveles de referencia indicados en la normativa vigente}

El nivel de referencia de concentración de radón para lugares de trabajo interiores es de $300 \mathrm{~Bq} / \mathrm{m}^{3}$, y ha sido establecido por la Unión Europea a través de la Directiva 2013/59/ EURATOM del Consejo de 5 de diciembre de 2013, por la que se establecen normas de seguridad básicas para la protección contra los peligros derivados de la exposición a radiaciones ionizantes. 
En el caso de superarse este umbral, los titulares o responsables de los centros de trabajo deberán contactar con una empresa experta en mitigación, que se encargará de estudiar el problema y plantear las soluciones oportunas.

En cualquier caso, la Guía de Seguridad 11.4 señala que en la protección frente al radón debe primar el principio de optimización, lo cual implica mantener las exposiciones de los trabajadores y el público tan bajas como sea razonablemente posible, teniendo en cuenta factores de la organización del trabajo, técnicos, sociales y económicos. Por tanto, si durante el estudio se identifican medidas de remedio que consigan reducir las exposiciones a un coste asumible para la instalación, estas deberán implementarse aún cuando los niveles medios de radón se encuentren por debajo del nivel de referencia.

\section{Recomendaciones de prevención y mitigación}

EL CSN indica que, en general, las medidas de remedio frente a concentraciones de radón que superen los umbrales establecidos en la normativa, pueden clasificarse en:

a) Soluciones constructivas, que incluyen la puesta en marcha de sistemas de extracción. En la publicación del CSN Protección frente a la inmisión de gas radón en edificios se analiza la capacidad de distintas medidas correctoras de este tipo para atenuar la inmisión de radón. 
b) Controles administrativos, dirigidos fundamentalmente a controlar los tiempos de permanencia o a restringir el acceso a las zonas con concentraciones de radón más elevadas. Siempre es preferible implantar medidas del primer tipo, aunque en los lugares de trabajo subterráneos esto suele ser más difícil o incluso inviable, como ocurre en las cuevas turísticas. Una vez se lleve a cabo cualquier solución constructiva deberán emprenderse nuevas mediciones que evalúen su efectividad. En el caso de que esta no sea la esperada, deberán analizarse las causas del fallo y plantearse, si es necesario, soluciones alternativas. Cuando se establezcan controles de tipo administrativo, siguiendo el principio de optimización, deberán tomarse especialmente en cuenta los trabajadores más sensibles (trabajadoras gestantes, menores de edad, trabajadores con enfermedad pulmonar...).

Para una mejor visualización y valoración de los resultados obtenidos en las campañas de medida de la concentración de radón en lugares de trabajo interiores, se propone un semáforo de 4 colores, verde, azul, naranja y rojo, atendiendo a la superación o no de umbrales o niveles de referencia de concentración media de radón $\left(C_{R n}\right)$ expresada en Bequerelios por metro cúbico $\left(\mathrm{Bq} / \mathrm{m}^{3}\right)$, medida en un lugar de trabajo interior durante un periodo de 3 meses. 


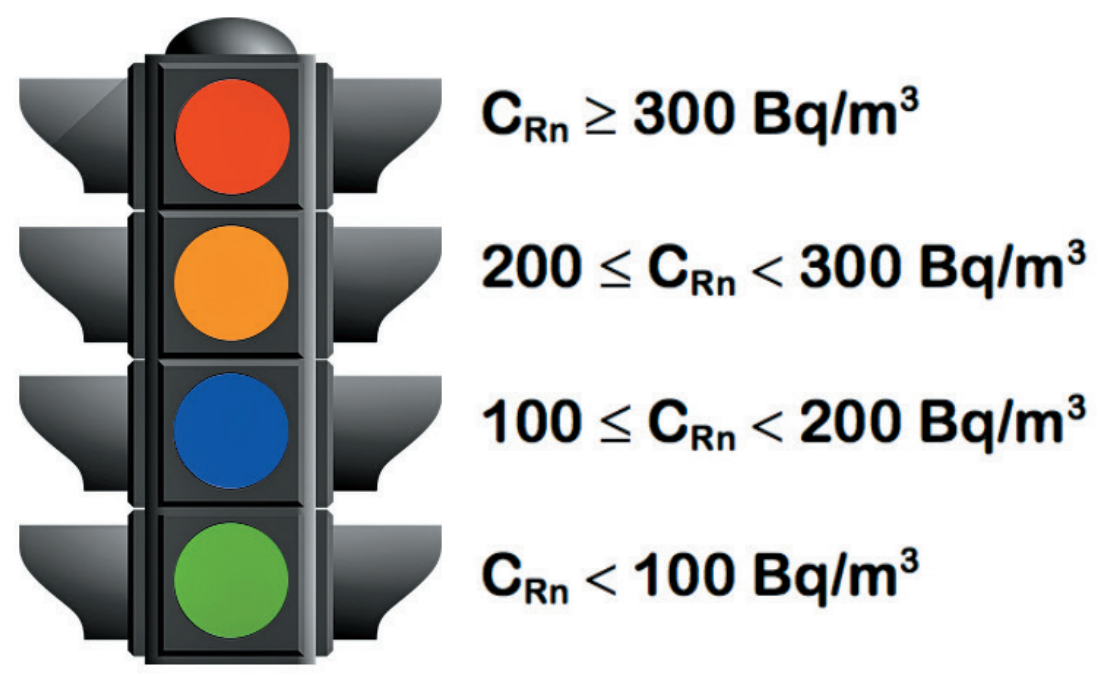

Semáforo de evaluación de resultados de medidas de la concentración de gas radón $(C R n)$ en lugares de trabajo interiores

La adopción de estos cuatro niveles de referencia se ha basado en los criterios establecidos por los organismos siguientes: OMS, CSN y Unión Europea (Directiva europea EURATOM). La explicación de los criterios de clasificación para cada color del semáforo es la siguiente:

a) Verde, $C_{R n}<100 \mathrm{~Bq} / \mathrm{m}^{3}$. Tanto la OMS como la directiva EURATOM indican que los descubrimientos epidemiológicos recientes de los estudios residenciales demuestran que existe un mayor riesgo estadísticamente significativo de padecer cáncer de pulmón derivado de la exposición prolongada al radón en recintos cerrados a niveles del orden de $100 \mathrm{~Bq} / \mathrm{m}^{3}$. Es por este motivo que el semáforo propuesto fija su valor inferior de referencia 
con el color verde para las medidas de la concentración de radón que sean inferiores a ese nivel de referencia.

b) Azul, $100 \leq C_{R n} \leq 200 \mathrm{~Bq} / \mathrm{m}^{3}$. Criterio adoptado a partir del mapa de potencial de radón en España y del mapa de zonas de actuación prioritaria elaborados por el CSN. Para el CSN, las zonas de actuación prioritaria son aquellas en que la población que reside en plantas bajas o primeras está expuesta, en promedio, a una concentración de unos $200 \mathrm{~Bq} / \mathrm{m}^{3}$ (casi tres veces más alta que el promedio para el resto de zonas), y más de un $10 \%$ de los edificios presenta niveles superiores a $300 \mathrm{~Bq} / \mathrm{m}^{3}$. Por tanto, el límite inferior de estas zonas se establece en $200 \mathrm{Bg} / \mathrm{m}^{3}$. El color azul del semáforo nos indicaría edificios que superan el valor inferior de referencia de la OMS $\left(100 \mathrm{~Bq} / \mathrm{m}^{3}\right)$, pero que no superan el valor de referencia del CSN para ser considerada zona de actuación prioritaria $\left(200 \mathrm{~Bq} / \mathrm{m}^{3}\right)$.

c) Naranja, $200 \leq C_{R n} \leq 300 \mathrm{~Bq} / \mathrm{m}^{3}$. Con el mismo criterio que el punto anterior, con el color naranja del semáforo indica concentraciones de radón propias de una zona de actuación prioritaria según el CSN.

d) Rojo, $C_{R n} \geq 300 \mathrm{~Bq} / \mathrm{m}^{3}$. El color rojo del semáforo se correspondería con los valores que igualen o superen los $300 \mathrm{~Bq} / \mathrm{m}^{3}$, ya que la Directiva la Unión Europea 2013/59/ EURATOM del Consejo de 5 de diciembre de 2013, que establece no deben superarse los $300 \mathrm{~Bq} / \mathrm{m}^{3}$ y que si los niveles son superiores, las actividades humanas realizadas dentro del lugar de trabajo no deben considerarse como prácticas. 
Para los lugares de trabajo que registren concentraciones de radón con valores rojos y naranjas de acuerdo con el semáforo de evaluación, se recomienda la implementación de medidas de remedio por parte de especialistas en la materia. Una vez implementadas, se recomienda realizar nuevas mediciones con detectores pasivos de trazas nucleares $y$, de persistir los valores altos de concentración de radón, es recomendable realizar un estudio exhaustivo con detectores activos de medida en continuo para localizar la fuente de entrada y las posibles fluctuaciones de la concentración de radón a lo largo del día, a la vez que se controlen simultáneamente otros parámetros ambientales como la temperatura y la presión atmosférica.

En la prevención juega un papel muy importante el formar e informar a los trabajadores y a los responsables públicos de los riesgos para la salud que supone la exposición al gas radón, mediante actividades formativas coordinadas por los titulares de los lugares de trabajo o las administraciones públicas.

\section{Bibliografía de consulta}

- Consejo de la Unión Europea (2014). Directiva 2013/59/ Euratom del Consejo de 5 de diciembre de 2013 por la que se establecen normas de seguridad básicas para la protección contra los peligros derivados de la exposición a radiaciones ionizantes, y se derogan las Directivas 89/618/Euratom, 90/641/Euratom, 96/29/Euratom, 97/43/ Euratom y 2003/122/Euratom. Diario Oficial de la Unión Europea 17.1.2014. ISSN 1977-0685. 
- Consejo de Seguridad Nuclear (2012). Instrucción IS-33, de 21 de diciembre de 2011, del Consejo de Seguridad Nuclear, sobre criterios radiológicos para la protección frente a la exposición a la radiación natural. BOE $n^{\circ} 22$ de 26.01.2012.

- Consejo de Seguridad Nuclear (2012). Guía de Seguridad 11.04 del CSN: Metodología para la evaluación de la exposición al radón en los lugares de trabajo.

- Consejo de Seguridad Nuclear (2010). Guía de Seguridad 11.01 del CSN: Directrices sobre la competencia de los laboratorios y servicios de medida de radón en aire.

- Frutos Vázquez, B., (2009). Estudio experimental sobre la efectividad y la viabilidad de distintas soluciones constructivas para reducir la conetración de gas radón en edificaciones. Tesis doctoral de la Universidad Politécnica de Madrid.

- Hernández L.E. et al. (2012). Radiology of Canarian volcanic rocks. Harmonising Rock Engineering and the Environment - Qian \& Zhou (eds) 2012. Taylor \& Francis Group, London, ISBN 978-0-415-80444-8. Pag. 641644.

- Ministerio de la Presidencia (2010). Real Decreto 1439/2010, de 5 de noviembre, por el que se modifica el Reglamento sobre protección sanitaria contra radiaciones ionizantes (RPSRI), aprobado por Real Decreto 783/2001, de 6 de julio (BOE núm. 279, de 18.11.2010). 
- Ministerio de Fomento (2018). Real Decreto 106/2018, de 9 de marzo, por el que se regula el Plan Estatal de Vivienda 2018-2021. (BOE Núm. 61, de 10.03.2018).

- Ministerio de Trabajo y Asuntos Sociales (2006). NTP 728: Exposición laboral a radiación natural. Notas Técnicas de Prevención del Instituto Nacional de Seguridad, Salud y Bienestar en el Trabajo (INSSBT).

- Ministerio de Trabajo y Asuntos Sociales (2006). Real Decreto 1299/2006, de 10 de noviembre, por el que se aprueba el cuadro de enfermedades profesionales en el sistema de la Seguridad Social y se establecen criterios para su notificación y registro.

- Ministerio de Trabajo y Asuntos Sociales (2003). NTP 614: Radiaciones ionizantes: normas de protección. Notas Técnicas de Prevención del Instituto Nacional de Seguridad, Salud y Bienestar en el Trabajo (INSSBT).

- Ministerio de Trabajo y Asuntos Sociales (1999). NTP 533: El radón y sus efectos sobre la salud. Notas Técnicas de Prevención del Instituto Nacional de Seguridad, Salud y Bienestar en el Trabajo (INSSBT).

- Ministerio de Trabajo y Asuntos Sociales (1997). NTP 440: Radón en ambientes interiores. Notas Técnicas de Prevención del Instituto Nacional de Seguridad, Salud y Bienestar en el Trabajo (INSSBT).

- Organización Mundial de la Salud, OMS (2015). Manual de la OMS sobre el radón en interiores. Una perspectiva 
de salud pública. Organización Mundial de la Salud. ISBN 9789243547671.

- Quindós Poncela, L. S. (1995). Radón, un gas radiactivo de origen natural en su casa. Universidad de Cantabria. Consejo de Seguridad Nuclear. ISBN 84-8102-114-8. 
